3-5-2019

\title{
"What's on the Test?": The Impact of Giving Students a Concept-List Study Guide
}

Patrick Cushen

Murray State University, pcushen@murraystate.edu

Jana Michelle Hackathorn

Murray State University, jhackathorn@murraystate.edu

Maria D. Vázquez Brown

Management Research Group

Sean Rife

Murray State University, srife1@murraystate.edu

Amanda Watson Joyce

Murray State University, awatson22@murraystate.edu

See next page for additional authors

Follow this and additional works at: https://digitalcommons.murraystate.edu/faculty

Part of the Educational Methods Commons, and the Psychology Commons

\section{Recommended Citation}

This is an Accepted Manuscript of an article published by Sage Journals in Teaching of Psychology on March, 5, 2019, available online: https://doi.org/10.1177/0098628319834171

This Peer Reviewed/Refereed Publication is brought to you for free and open access by Murray State's Digital Commons. It has been accepted for inclusion in Faculty \& Staff Research and Creative Activity by an authorized administrator of Murray State's Digital Commons. For more information,

please contact msu.digitalcommons@murraystate.edu. 


\section{Authors}

Patrick Cushen; Jana Michelle Hackathorn; Maria D. Vázquez Brown; Sean Rife; Amanda Watson Joyce; Eric D. Smith; Dr. Michael Bordieri, PhD; Paul W. Anderson; Marie E. Kalsson; and Jordan Daniels 
"What's on the Test?": The Impact of Giving Students a Concept-list Study Guide Patrick J. Cushen ${ }^{1}$, Jana Hackathorn ${ }^{1}$, Maria D. Vázquez Brown ${ }^{1}$, Sean C. Rife ${ }^{1}$, Amanda W. Joyce $^{1}$, Eric D. Smith ${ }^{2}$, Michael J. Bordieri ${ }^{1}$, Paul W. Anderson ${ }^{1}$, Marie Karlsson ${ }^{1}$, \& Jordan Daniels $^{1}$ Murray State University ${ }^{1}$, University of Arizona ${ }^{2}$

Author Note:

Patrick J. Cushen, Department of Psychology, Murray State University; Jana Hackathorn, Department of Psychology, Murray State University; Maria D. Vázquez Brown, Department of Psychology, Murray State University; Sean C. Rife, Department of Psychology, Murray State University; Amanda W. Joyce, Department of Psychology, Murray State University; Eric D. Smith, Department of Educational Psychology, University of Arizona; Michael Bordieri, Department of Psychology, Murray State University; Paul W. Anderson, Department of Psychology, Murray State University; Marie Karlsson, Department of Psychology, Murray State University; Jordan Daniels, Department of Psychology, Murray State University. Correspondence concerning this article should be address to Patrick J. Cushen, Department of Psychology, Murray State University, 212 Wells Hall, Murray, KY 42071. Email: pcushen@murraystate.edu 


\begin{abstract}
Students frequently request concept-list study guides prior to exams, but the benefits of instructors providing such resources are unclear. Research on memory and comprehension has suggested that some challenges in learning are associated with benefits to performance. In the context of an introductory psychology course, a study was conducted to investigate the impact of providing a concept-list study guide on exam performance, as opposed to having students create a study guide. Additionally, student preferences for various types of study guides were examined. Results indicated that although students greatly prefer that the instructors provide a study guide (as opposed to making their own), providing a concept-list study guide resulted in poorer exam performance. These results call for future research on the influence of study guides on student performance.
\end{abstract}

Keywords: teaching psychology, study aids, study guides, exam performance 
"What's on the Test?": The Impact of Giving Students a Concept-list Study Guide

Students frequently request study guides prior to exams. Although many instructors do provide them, it is unclear if they are actually helpful. Given how common these requests are, there is surprisingly little research on students' perceptions of, or benefits from, instructorprovided study guides. This research investigated the benefits of a concept-list study guide and student preferences for different guide formats.

Arguably, a developed strategy or aid should help students to perform better on exams. Credé and Kuncel (2008) conducted a meta-analysis of 344 studies and found that students' selfreported study strategies were generally predictive of GPA, even after considering individual differences in cognitive ability. Dunlosky, Rawson, Marsh, Nathan, and Willingham (2013) identified self-testing and distributed practice as the most beneficial study strategies, with elaborative and explanatory techniques considered moderately beneficial. The least beneficial techniques included non-processing study strategies such as highlighting, mnemonic use, and simple rereading.

Unfortunately, several studies have indicated that students tend to make poor use of available aids, and consistently find that students rely heavily on boldfaced or italicized terms and on glossaries (Gurung, 2003; Marek, Griggs, \& Chrisopher, 1999; Weiten, Deguara, Rehmke, \& Sewell, 1999; Weiten, Guadagno, \& Beck, 1996). Use of those elements frequently does not predict exam performance, although students still tend to report them as being helpful (Balch, 2001; Gurung, 2003; 2004; Weiten et al., 1996; Weiten et al., 1999). Moreover, in an analysis of learning aid use and exam performance, Gurung (2003) found that students' ratings of the helpfulness of "key terms" provided in textbooks was negatively related to exam performance. Combined with students' consistent emphasis on bolded terms and definitions, this 
finding suggests that students may be more likely to use study aids to reinforce superficial factual knowledge and not the conceptual and applied understanding that can also be assessed on exams. Consistent with this idea, several studies have found that discussion questions and review exercises are amongst the least likely study aids to be used by students (Marek et al., 1999; Weiten et al., 1996; Weiten et al., 1999), despite self-testing for understanding being one of the more helpful strategies for learning (Dunlosky et al., 2013; Gurung, 2003).

There is even evidence to suggest that students will not make appropriate use of challenging study strategies that they know to be beneficial. For example, Susser and McCabe (2013) found that students were generally aware of the advantages of engaging in spaced studying (i.e. distributing study across multiple sessions), and indicated that they would use it under ideal circumstances. However, in practice, they reported low use of space study and tended to favor more common study strategies such as rereading their notes or the book. Ultimately, the existing research indicates a mismatch between what strategies students will use to aid their learning and what will actually improve their knowledge and understanding.

Despite the availability of their own notes, possibly lecture slides, and the study aids in their textbooks, it is the authors' experiences that students frequently request their instructors provide study guides indicating what will be on the exam (i.e., a list of concepts to study). However, reviewing course materials and determining what is most important without the direction of the instructor may serve as a desirable difficulty (Bjork \& Bjork, 2011) that increases processing of the material. According to Craik and Lockhart's levels of processing framework (Craik \& Lockhart, 1972), deeper processing of information leads to stronger memory traces that could possibly improve immediate exam performance and long-term 
retention of information. Providing students with a concept-list study guide may discourage their engaging in the more complex processing necessary for them to guide their own study.

There are several components of having to direct and regulate one's own study that might lead to more complex processing. For example, personally generating to-be-remembered information leads to better memory than simply receiving that information, a phenomenon known as the "generation effect" (Chi \& Wylie, 2014; Dunlosky et al., 2013; Slamecka \& Graf, 1978). Students may also be more likely to engage in beneficial processes like self-explanation (Chi, Leeuw, Chiu, \& Lavancher, 1994; Chi, 2000) or concept mapping (Novak, 1990), both of which have been shown to facilitate memory and help to improve metacomprehension and metamemory — students' understanding of their comprehension of and memory for the material respectively (Chi et al., 1994; Griffin, Wiley, \& Thiede, 2008; Wiley, Griffin, Jaeger, Jarosz, Cushen, \& Thiede, 2016).

In many ways, the benefits associated with students creating their own study guides could be similar to the benefits associated with the testing effect (Einstein, Mullet, \& Harrison, 2012; Karpicke \& Roediger, 2008; Roediger \& Karpicke, 2006). In the testing effect, information is recalled better if it had been previously tested than if it had simply been restudied. Roediger and Karpicke (2006) categorize the effects of testing as either direct or mediated. Direct effects refer specifically to the influence of having to retrieve information prior to a later assessment. Mediated effects refer to changes that may occur if a person is allowed to restudy after an initial test. Recently, Pyc and Rawson (2012) have suggested that one of the mechanisms of mediated effects may be that testing may help people to change their learning or memory strategies if necessary. Similarly, it is possible that providing students with study guides prevents them from 
engaging in strategy shifts that might occur as a result of being challenged with guiding their own studying.

The goal of the research reported in this paper was to investigate the impact on exam performance of providing students with a concept list prior to an exam as compared to not providing a concept list and suggesting they construct their own study guides. The impact of receiving an instructor-provided concept list was examined using a within-subjects design across 4 sections of an introductory psychology course for which students were either provided a concept list or advised to create their own study guide prior to the first two exams of the semester. Whether students received a concept list for the first or second exam was counterbalanced across course sections and the impact of those guides was assessed via questions embedded in the exams. Students were asked the same questions a second time at the end of the semester to evaluate long-term retention.

It was hypothesized that providing students with a concept list study guide would result in poorer performance on the initial exam assessments and might lead to poorer long-term retention than instructing students to create their own study guides.

\section{Method}

\section{Participants}

Participants were students $(N=237)$ enrolled in one of four introductory psychology courses at a Midwestern regional state university. However, 35 individuals were excluded from analysis due to missing one or both of the class exams containing items for this study, resulting in a sample of 202 individuals. Of that sample, 113 (55.9\%) were freshmen, 54 (26.7\%) were sophomores, 22 (10.9\%) were juniors, and 13 (6.4\%) were seniors. Additional demographic information was collected via an online self-report measure completed towards the end of the 
course, which 50 students did not complete. Of the 152 students who completed the survey, there were 103 females $(67.8 \%)$ and 46 males $(30.3 \%)$. The vast majority of the students were Caucasian/white $(132,86.8 \%)$, but other ethnicities were also represented: AfricanAmerican/black (8, 5.3\%), Asian/Pacific Islander (1, 0.6\%), Hispanic (2, 1.3\%), biracial (5, $3.3 \%)$, and 4 "other" $(2.6 \%)$.

\section{Materials and Procedure}

Prior to the start of the semester, each of the four sections was randomly assigned the order in which study guides would be made available. A different member of the psychology faculty taught each of the four sections. Counterbalanced across the first two exams, students were either given a concept list that identified what topics were covered on the exam (Concept List condition), or were not provided with a guide and were encouraged to generate a study guide from their notes (Control condition). That is, two of the course sections presented students with a teacher-generated study guide for the first exam, and provided them with no study guide for the second exam. Conversely, the remaining two sections provided students with a study guide for the second exam but not the first exam. This counterbalance was conducted to buffer out potential order (e.g. practice) effects on exams.

Several weeks before the first exam, students were presented with an informed consent form by a graduate assistant, and told that the instructor for the course would be investigating the effectiveness of various teaching strategies throughout the semester. Consent forms were kept by the graduate assistant and not shown to the instructors until after the end of the semester.

For the first two exams across the sections, all instructors covered the same content areas. Specifically, instructors covered the brain and research methods in the first exam, and learning and memory in the second exam. Then students' knowledge, comprehension, and application of 
those topics was assessed via questions incorporated into the exams. All students received these exam questions as part of their course grade, and regardless of consent to participate.

Across all course sections, nine questions were embedded into each of the first two exams. Questions were distributed across the first three levels of Bloom's taxonomy (i.e, knowledge, comprehension, and application; Bloom, Engelhart, Furst, Hill, \& Krathwohl, 1956), with three questions per level.

Finally, at the end of the semester, students completed a brief survey that included an unexpected test of the same 18 questions from the two exams, to measure long-term retention. Additionally, students were asked a series of open-ended questions regarding their preferences for instructor-generated study guides and student-generated study guides. They were also asked if they used study guides during the semester to study, and if they could go back to the beginning of the semester would they change their study strategies, and how.

\section{Results}

Our analyses focused on the differences between study guide sources in two areas: immediate exam performance and long-term retention. As questions were divided according to Bloom's taxonomy (Bloom et al., 1956), we next conducted analyses to test whether providing a study guide had specific effects based on the taxonomic level of the question. We also tested whether there were any order effects that influenced how participants performed in either the Concept List (CL) or Control conditions. Finally, we assessed student preferences for receiving or not receiving an instructor-provided study guide.

\section{Immediate Exam Performance}

A paired-samples t-test was used to evaluate whether there was a difference in accuracy for the CL versus Control conditions. This analysis indicated that accuracy was higher for students 
in the Control condition $(M=5.29, S D=2.10)$ compared to the Concept List condition $(M=4.77$, $S D=2.16), t(201)=3.81, p<.001, d=.24$. In other words, when students were not provided with study guides and advised to create their own, they scored higher on the exam questions than when given a study exam by the instructor (e.g., a concept list).

A factorial ANOVA was used to test whether the effect of the study guide condition was moderated by the taxonomic level of the exam questions. This analysis revealed no significant interaction between study guide condition and question level, $F(2,402)=.97, p=.38, \eta_{\mathrm{p}}{ }^{2}=.005$, indicating no differences between question types based on study guide condition. Taken together, students performed better on exams when left to generate their own study guides than when given a concept list by the instructor. This was true across the different levels of Bloom's taxonomy (i.e., knowledge, comprehension, and application; Bloom, et al., 1956).

Finally, independent samples t-tests were used to assess whether there were order effects on accuracy in either condition (Concept List or Control). Results indicated that performance in the Concept List condition was only marginally influenced by whether students were provided with that concept list on the first exam $(M=5.07, S D=1.85)$ or on the second exam $(M=4.50$, $S D=2.38), t(200)=1.90, p=.059, d=.27$. However, performance in the Control condition was significantly higher when students were advised to create their own study guide on the second exam $(M=6.17, S D=1.65)$ compared to the first exam $(M=4.49, S D=2.16), t(200)=6.15, p$ $<.001, d=.87$. These results suggested that advising students to create their own study guide was more beneficial if they had previously received a concept list as part of a prior exam. This interaction was also confirmed by a factorial ANOVA, $F(1,400)=30.57, p<.001, \eta_{\mathrm{p}}{ }^{2}=.071$.. However, these results were not explicitly hypothesized and the exact cause of this effect is 
unclear. Future research would benefit from further-examining the role of prior experience on the use of study guides.

\section{Retention Performance}

Another paired-samples t-test was used to evaluate whether there was a difference in performance on the retention test based on study guide condition. Eighteen people were excluded from this retention analysis due to missing data, resulting in a sample of 184 . This analysis failed to find any significant differences between retention performance for material from the Control condition $(M=5.23, S D=1.42)$ or for the material from the Concept List condition $(M=5.43$, $S D=1.58), t(183)=-1.56, p=.12, d=.13$.

There was also no significant interaction between study guide condition and the taxonomic level of the questions on long-term retention, $F(2,366)=.55, p=.58, \eta_{\mathrm{p}}{ }^{2}=.003$. In conclusion, these analyses did not show any difference in long-term retention of class material for students when they generated their own study guide versus when they were provided with concept lists by the instructor. Again, there were also no differences based on the type of question utilized (i.e., knowledge, comprehension, and application; Bloom, et al., 1956).

Given that retention data was only viable for $91 \%$ of participants, we wanted to make sure that the difference between the significant effect in initial exam performance and the nonsignificant effect in retention performance was not due to the analyses being on different groups due to attrition. An additional paired-samples t-test was conducted to check whether the difference between the Concept List and Control conditions on immediate exam performance remained significant in the subset of participants who completed the retention test. This analysis confirmed a significant difference in exam performance as a result of study guide condition on immediate exam performance for this group, $t(183)=3.96, p<.001, d=.26$. In other words, students who 
completed the exam questions used for this study at all three time points (i.e., following the first two exams as well as for the retention component), showed the same effect as those who only completed part of the study (e.g., missing the retention data). In sum, students performed better on exam questions when being told to create their own study guides as opposed to when given study guides by the instructor.

As was the case with immediate exam performance, order effects were tested using two independent samples t-tests. Results indicated that with respect to long-term retention, on questions for which students were advised to create their own study guide, those students who were in the Control condition for the first exam $(M=5.28, S D=1.52)$ did not differ from those who were in that condition for the second exam $(M=5.19, S D=1.31), t(183)=.47, p=.637, d=$ .063. However, on questions for which students were provided a concept list, those who were in the Concept List condition on the first exam $(M=4.63, S D=1.18)$ performed worse than those in the concept list condition on the second exam $(M=6.18, S D=1.54), t(183)=7.62, p<.001, d=$ 1.13. This interaction was also confirmed by a factorial ANOVA, $F(1,366)=24.81, p<.001, \eta_{\mathrm{p}}{ }^{2}$ $=.063$. Again, these results were not hypothesized and the exact cause of this effect is unclear. Future research should investigate whether this is a consistent effect.

\section{Student Preference}

Of those students who self-reported a study guide preference $(N=144), 87$ students (60.4\%) reported a preference for receiving a concept list, 41 students (28.5\%) reported a preference for their self-generated guide, 9 students (6.3\%) reported preferring neither option, and 7 students (4.9\%) reported preferring both equally or having no preference.

Those students who reported a preference for a self-generated guide did show significantly better performance on the Control condition exam $(M=5.44, S D=2.20)$ compared to the Concept 
List condition exam $(M=4.66, S D=2.18), t(40)=2.72, p=.01, d=.36$. However, students reporting a preference for receiving the concept list also showed an advantage on the Control condition $(M=5.59, S D=1.94)$ compared to the Concept List condition exam $(M=5.11, S D=$ 1.96), $t(86)=2.34, p=.02, d=.45$. These results indicate that students performed better when advised to create their own study guides, and that this advantage did not seem to depend on whether they preferred constructing their own or receiving an instructor-provided guide.

\section{Discussion}

As hypothesized, students performed better in the Control condition than in the Concept List condition. Despite better performance when not receiving a concept list, the majority of students reported having preferred receiving a concept list. This result is consistent with prior studies indicating that students do not know what study aids are actually helpful to their performance and may make poor choices in what aids they want or use (e.g. Gurung, 2004).

The relative lack of effects for long-term retention may not be surprising, given that students were not expecting a test of the material and the retest was purely for the purposes of research and did not affect their test grades. Moreover, retention of information in introductory classes is generally poor. A recent meta-analysis of college classes, which included psychology courses, indicated that one-third of learned factual based knowledge is lost within the first year, and over half after that (Custers, 2010) and then almost all of it (approximately 80\%) in the lifetime (Custers \& Ten Cate, 2011). An interesting question for future research is whether the effects of advising students to create their own study guides would have similar effects on long-term retention as on immediate exam performance if the students anticipate receiving a retention test or that retention test is higher stakes. 
Importantly, although the control condition was advised to create their own study guides, those guides were not graded or collected. Thus, we do not know if the self-created study guides were of high quality or even if they were created at all. This leaves some ambiguity in why the conditions were different. If students in the control condition carefully created study guides, then these results are consistent with the expected impact of the self-generation effect (Slamecka \& Graf, 1978) or other kinds of deeper processing of information (Craik \& Lockhart, 1972). Without the aid of a study guide, students are forced to make their own decisions about what concepts are most critical to study and independently determined how best to focus their efforts. As previously suggested, this demand may lead to a variety of beneficial strategies including self-generation (Chi \& Wylie, 2014; Dunlosky et al., 2013), self-explanation (Chi, 2000), concept mapping (Novak, 1990), or self-testing (Roediger \& Karpicke, 2006) that may not only improve their memory and comprehension of material but may also lead to additional metacognitive processes (Griffin, Wiley, \& Thiede, 2008) that can lead to improved study strategies. These results would also be consistent with those of a recent study (Larson, Butler, \& Roediger, 2013) in which students who were given a review sheet (without asking them to generate any self-explanations or examples) performed significantly worse than those asked to generate self-explanations. Additionally, combining testing and self-explanations produced superior retention and application of knowledge (Larsen, Butler, \& Roediger III, 2013).

If, instead, students in the control condition did not create study guides, then these results may suggest that the mere presence of a study guide was detrimental to students. For example, providing students with a concept-list study guide might allow them to become overly-confident in their knowledge. Overconfidence in one's own knowledge is associated with a decreased likelihood of adjusting one's response when provided with feedback (Mannews \& Moore, 2013). 
In this study, students provided with a study guide could have been less likely to recognize and correct errors in their own understanding of course material. Regardless of the mechanism, this research has importantly demonstrated that students who are encouraged to create their own study guide, in comparison to their peers who are provided with a concept-list study guide, are at an advantage in terms of their exam performance. Future research that includes the collection and analysis of student-generated study guides would help to clarify whether and to what degree these different mechanisms are responsible for these group differences.

Despite the difference in performance between those that received a study guide and those advised to create their own, a majority of the students indicated a preference for receiving an instructor-provided concept list. Although concept lists may not be beneficial study aids, instructors often provide study guides in other formats. Based on the desire that students show for receiving instructor-provided study guides, we were interested in better understanding which study guides students prefer to use out of a broader set of options. To obtain additional information about this topic, we followed up the current study by querying a separate group of introductory psychology students in a later semester. The results of that study ${ }^{1}$ indicated that the

\section{${ }^{1}$ Students $(n=173)$ in seven introductory psychology courses reported their preferred} study guide source (i.e., instructor-provided, student-created, or none) and their preference of six types of instructor-provided study guides (i.e., simple concept list (CL), CL with definitions, CL with examples, CL with definitions and examples, CL organized by topic, or several textbook paragraphs). Results indicate they preferred instructor-provided to student-created guides 10 to 1. Also, they most preferred the CL with definitions and examples (78.8\%), whereas textbook excerpts (44\%) and simple concept lists (36.8\%) were least preferred. 
vast majority of students preferred instructor-provided study guides to self-created guides. Moreover, students preferred a concept list that contained definitions and examples. That is, students reported preferring what should be the contents of their class notes, but what would also help them study with the least amount of effort. Student reported disliking study guide formats that would require the most amount of student effort, including additional summarization or elaboration.

Together, the study and follow-up show a definite disconnect between what students prefer and what they need to perform well. Despite performing more poorly when provided with a concept-list study guide, students demonstrated a clear subjective preference for this less beneficial condition. Then, in the follow-up collection, students demonstrated a preference for information rich instructor-provided review materials. Study guides that include definitions and applications require the least amount of student input or effort, and thus may be viewed by students as more efficient aids to studying, despite possibly providing fewer benefits to learning.

There were a few limitations to the current study. First, as noted earlier, the studentcreated study guides were not collected, graded, nor analyzed. It is possible that some students created poor quality studies guides or did not create a study guide at all. As such, it remains to be seen whether the differences between conditions is due to the fact that creating a study guide is beneficial, that receiving a concept list is detrimental, or a combination of the two. Future studies might include qualitatively analyzing the study guides that students self-generate in order to understand which types of those guides are most or least effective. Instructors could then provide better guidance for students to take control of their own exam preparation. Additionally, participants in this study were not explicitly informed of the benefits of the efforts that result from student-created study guides. An interesting open question is whether being made aware of 
this knowledge might incentivize students to use study guides differently or whether they would persist in using less efficient strategies even when aware that other strategies are more beneficial (e.g. Susser \& McCabe, 2013).

Additionally, while providing students with a concept list study guide did not appear beneficial in the current study, this does not imply that any kind of study guide would be detrimental. There is relatively little systematic research on what types of study guides could or should be given to students. Moreover, when asked what types of guides they prefer to receive, students tended to indicate that they would rather have more complex guides (e.g. including definitions and examples). An interesting area of future research may be to investigate whether these student-preferred guides result in better exam performance. Importantly, considering the amount of elaboration that would already be included in such a guide, it is entirely possible that these guides may result in worse performance as they allow students to get away with even less self-generation or explanation than a simple concept list.

Finally, a few order effects were identified that somewhat complicate the main effects of study guide condition. It is possible that the particular advantage to giving a concept list first may attributed to students having had a chance to gain a better understanding of the type of content the instructors considered to be important and the types of questions presented on the exams. Students who created their own study guides for the first exam would not have had that context to optimize their studying. This suggests that students need advising on what should be included in effective study guides.

However, a different order effect was seen for the long-term retention where material from the concept-list condition was better remembered on the retention test if the students were given instructions to create their own study guide on the prior exam. One possible, though purely 
speculative, explanation for this difference may be that the effort to create their own study guide on the first exam helped them to make better use of the concept list on the second exam, leading to better long-term retention. However, these effects were not hypothesized and are inconsistent with the pattern of results for immediate exam performance. Order was counterbalanced in this study specifically to mitigate it as a confound, but it was not the intention of this research to specifically study the effects of order. Future studies should more systematically investigate whether exam performance and long-term retention can be influenced by providing students with particular sequences of study aids.

Ultimately, the current study is unique in many ways. First, the conditions were randomly assigned and counterbalanced, yet still occurred in the classroom. This allows for increased internal validity as well as ecological validity in our scholarship of teaching and learning. Second, this study provides evidence of a generalization of cognitive effects primarily studied in the laboratory (e.g. generation, self-explanation, and self-testing) into the classroom setting. Finally, the results of this study call on teachers to reflect on the implications when students inevitably ask for a study guide. Although there is much more research needed in this area, their response could potentially help or hinder student success. 


\section{References}

Balch, W. R. (2001). Study tips: How helpful do introductory psychology students find them? Teaching of Psychology, 28, 272-274.

Begg, I., Snider, A., Foley, F., \& Goddard, R. (1989). The generation effect is no artifact: Generating makes words distinctive. Journal of Experimental Psychology: Learning, Memory, and Cognition, 15, 977-989.

Bjork, E. L., \& Bjork, R. A. (2011). Making things hard on yourself, but in a good way: Creating desirable difficulties to enhance learning. In M. A. Gernsbacher, R. W. Pew, L. M. Hough, \& J. R. Pomerantz (Eds.), Psychology and the real world: Essays illustrating fundamental contributions to society (pp. 56-64). New York: Worth Publishers.

Bloom, B. S., Englehart, M. D., Hill, W. H., Furst, E. J., \& Krathwohl, D. R. (1956). Taxonomy of educational objectives: Handbook 1. The cognitive domain. New York: McKay.

Chi, M. T. H. (2000). Self-explaining expository texts: The dual processes of generating inferences and repairing mental models. In R. Glaser (Ed.), Advances in Instructional Psychology, (pp. 161-237). Mahwah, NJ: Erlbaum.

Chi, M. T. H., DeLeeuw, N., Chiu, M., \& LaVancher, C. (1994). Eliciting self-explanations improves understanding. Cognitive Science, 18, 439-477.

Chi, M. T. H., \& Wylie, R. (2014). The ICAP Framework: Linking cognitive engagement to active learning outcomes. Educational Psychologist, 49, 219-243.

Craik, F. I. M., \& Lockhart, R. S. (1972). Levels of processing: A framework for memory research. Journal of Verbal Learning and Verbal Behavior, 11, 671-684. 
Credé, M., \& Kuncel, N. R. (2008). Study habits, skills, and attitudes: The third pillar supporting collegiate academic performance. Perspectives on Psychological Science, 3, 425-453. doi: 10.1111/j.1745-6924.2008.00089.x

Custers, E. J. F. M. (2010). Long-term retention of basic science knowledge: a review study. Advances in Health Sciences Education, 15(1), 109-128.

Custers, E. J. F. M, \& Ten Cate, O. T. J. (2011). Very long-term retention of basic science knowledge in doctors after graduation. Medical Education, 45, 422-430.

Dunlosky, J., Rawson, K. A., Marsh, E. J., Nathan, M. J., \& Willingham, D. T. (2013). Improving students' learning with effective learning techniques: Promising directions from cognitive and educational psychology. Psychological Science in the Public Interest, 14, 4-58. doi: 10.1177/1529100612453266

Einstein, G. O., Mullet, H. G., \& Harrison, T. L. (2012). The testing effect: Illustrating a fundamental concept and changing study strategies. Teaching of Psychology, 39, 190193.

Griffin, T. D., Wiley, J., \& Thiede, K. W. (2008). Individual differences, rereading, and selfexplanation: Concurrent processing and cue validity as constraints on metacomprehension accuracy. Memory \& Cognition, 36, 93-103.

Gurung, R. A. R. (2003). Pedagogical aids and student performance. Teaching of Psychology, $30,92-95$.

Gurung, R. A. R. (2004). Pedagogical aids: Learning enhancers or dangerous detours? Teaching of Psychology, 31, 164-166. 
Karpicke, J. D., \& Roediger, H. L. (2008). The critical importance of retrieval for learning. Science, 319, 966-968.

Larsen, D. P., Butler, A. C., \& Roediger, H. L. (2013). Comparative effects of test-enhanced learning and self-explanation on long-term retention. Medical Education, 47(7), 674-682.

Mannes, A. E., \& Moore, D. A. (2013). A behavioral demonstration of overconfidence in judgment. Psychological science, 24, 1190-1197.

Marek, P., Griggs, R. A., \& Christopher, A. N. (1999). Pedagogical aids in textbooks: Do college students' perceptions justify their prevalence? Teaching of Psychology, 26, 11-19.

Mueller, P. A., \& Oppenheimer, D. M. (2014). The pen is mightier than the keyboard: Advantages of longhand over laptop note taking. Psychological Science, 25, 1159-1168. doi: $10.1177 / 0956797614524581$

Novak, J. D. (1990). Concept mapping: A useful tool for science education. Journal of Research in Science Teaching, 27, 937-949.

Pyc, M. A., \& Rawson, K. A. (2012). Why is test-restudy practice beneficial for memory? An evaluation of the mediator shift hypothesis. Journal of Experimental Psychology: Learning, Memory, and Cognition, 38, 737-746.

Roediger, H. L., \& Karpicke, J. D. (2006). The power of testing memory: Basic research and implications for educational practice. Perspectives on Psychological Science, 1, 181-210.

Slamecka, N. J., \& Graf, P. (1978). The generation effect: Delineation of a phenomenon. Journal of Experimental Psychology: Human Learning and Memory, 4, 592-604. 
Susser, J. A., \& McCabe, J. (2013). From the lab to the dorm room: Metacognitive awareness and use of spaced study. Instructional Science, 41, 345-363.

Weiten, W., Deguara, D., Rehmke, E., \& Sewell, L. (1999). University, community college, and high school students' evaluations of textbook pedagogical aids. Teaching of Psychology, $26,19-21$.

Weiten, W., Guadagno, R. E., \& Beck, C. A. (1996). Students perceptions of textbook pedagogical aids. Teaching of Psychology, 23, 105-107.

Wiley, J., Grififn, T. D., Jaeger, A. J., Jarosz, A. F., Cushen, P. J., \& Thiede, K. W. (2016). Improving metacomprehension accuracy an undergraduate course context. Journal of Experimental Psychology: Applied, 22, 393-405.

Winograd, E. (1981). Elaboration and distinctiveness in memory for faces. Journal of Experimental Psychology: Human Learning and Memory, 7, 181-190. 